\title{
Eksplorasi Etnomatematika Makna Simbol Pakaian Pernikahan Adat Buton Kajian Semiotik
}

\author{
Dewi Sartika Sri Wulandari RH ${ }^{1}$, Fatma Erlianti Djafar ${ }^{1}$, Elfira Damayanti ${ }^{1}$, Nur Haliza ${ }^{1}$, Risna \\ Karim $^{1}$, La Eru Ugi ${ }^{2}$ \\ 1. Mahasiswa Program Studi Matematika Universitas Dayanu Ikhsanuddin Baubau \\ 2. Dosen Program Studi Matematika Universitas Dayanu Ikhsanuddin Baubau \\ e-mail:dewiw4733@gmail.com \\ (Received: 17-09-2021 : Reviewed: 20-10-2021 : Accepted: 22-10-2021)
}

\begin{abstract}
Abstrak
Matematika dan budaya disatukan dalam suatu cabang ilmu yang dikenal dengan "Etnomatematika". Etnomatematika merupakan penghubung dunia matematika dan budaya lokal. Salah satu budaya lokal suku Buton yakni pakaian pernikahan adat Buton memuat simbol-simbol yang dapat merepresentasikan unsur-unsur matematika. Unsurunsur matematika tersebut dapat ditemukan baik pada pakaian pernikahan adat pria maupun wanita. Tujuan penelitian ini adalah untuk mengetahui makna simbolik kajian semiotik dan konsep matematika pada pakaian pernikahan adat Buton. Penelitian ini merupakan jenis penelitian kualitatif yang bersifat eksploratif. Teknik pengumpulan data dalam penelitian ini adalah studi kepustakaan, observasi, wawancara dan dokumentasi. Wawancara dilakukan dengan mencari narasumber terpercaya dengan tetap memperhatikan protokol kesehatan. Pengujian validitas data dalam penelitian ini menggunakan triangulasi sumber dengan teknik cross-check. Hasil penelitian ini menunjukkan bahwa terdapat makna simbolik kajian semiotik yang merepresentasikan pakaian pernikahan adat Buton
\end{abstract}

Kata Kunci : Etnomatematika, Makna Simbol, Pakaian Pernikahan Adat Buton, Kajian Semiotik

\begin{abstract}
Mathematics and culture are united in a branch of science "Ethnomathematics". Ethnomathematics is a link between the world of mathematics and local culture. One of the local cultures of the Buton tribe, namely Buton traditional wedding clothes, contains symbols that can represent mathematical elements. These mathematical elements can be found in both men's and women's traditional wedding attire. The purpose of this study was to determine the symbolic meaning of semiotic studies and mathematical concepts in Buton traditional wedding attire. This research is a type of qualitative research that is exploratory. Data collection techniques in this study are literature study, observation, interviews and documentation. Interviews were conducted by looking for trusted sources while still paying attention to health protocols. Testing the validity of the data in this study used source triangulation with a cross-check technique. The results of this study indicate that there is a symbolic meaning of semiotic studies that represents the traditional wedding dress of Buton.
\end{abstract}

Keywords: Ethnomathematics, Symbol Meaning, Buton Traditional Wedding Attire, Semiotic Studies

\section{PENDAHULUAN}

Matematika dan budaya merupakan dua hal yang tidak dapat dipisahkan. Dari awal ditemukan, matematika terus berkembang secara dinamis seiring dengan perubahan zaman. Perkembangannya tidak pernah berhenti karena matematika akan terus berada dalam berbagai sisi kehidupan manusia. Hal ini sejalan dengan yang diungkapkan oleh (Bishop, 1994) bahwa matematika adalah bentuk budaya yang telah menyatu pada semua aspek kehidupan manusia. 
Namun, seringkali di masyarakat kita menemukan anggapan bahwa antara budaya dan matematika itu terpisah. Padahal tanpa disadari, sejak lama masyarakat telah melakukan kegiatan yang menggunakan konsep matematika seperti berhitung di dalam aktivitas sehari-hari.

Matematika dan budaya disatukan dalam cabang ilmu yang kita kenal dengan nama "etnomatematika". Risdiyanti \& Prahman (2017), mengungkapkan bahwa etnomatematika dapat dikatakan sebagai penghubung antara matematika dengan budaya lokal. Budaya lokal yang dimaksud tentunya banyak sekali. Salah satunya berupa simbol yang dapat kita temukan dalam budaya Buton. Simbol merupakan salah satu ungkapan kebudayaan manusia. Dengan simbol, kita dapat merepresentasikan hal-hal dari dunia. Kesalahan terbesar masyarakat dalam memahami simbol adalah menganggap bahwa simbol adalah subtansi. Sehingga seseorang seringkali terjebak dalam kebenaran semua hal yang hanya bersifat kasat mata sebagai kebenaran hakiki. Akan tetapi, tidak semua bentuk simbol berupa benda kasat mata, namun juga dapat melalui pakaian, gerakan dan ucapan. Simbol dapat dijadikan sebagai salah satu infrastruktur bahasa atau yang lebih kita kenal dengan bahasa simbol. Bahasa simbol dalam matematika seperti yang diungkapkan oleh Mulyono (2003) adalah bahasa simbolis yang fungsi praktisnya untuk mengekspresikan hubunganhubungan kuantitatif dan keruangan sehingga fungsi teoritisnya adalah untuk memudahkan berfikir.

Bahasa simbol dalam matematika ini dapat kita temukan pada salah satu unsur budaya Buton. Contohnya yakni pada pakaian adat pernikahan. Pakaian adat pernikahan bagi masyarakat Buton mempunyai makna khusus. Dalam artian bahwa masyarakat yang menggunakan pakaian adat tersebut, dengan ciri-ciri atau spesifikasi tertentu baik warna, bentuk perhiasan, dan jumlah aksesoris yang digunakan maupun perlengkapan lainnya adalah mereka yang memiliki status sosial yang lebih tinggi dalam tingkat kehidupan masyarakat Buton. Perbedaan status sosial ini sudah terjadi pada masa lampau maupun saat ini.

Pakaian adat pernikahan Buton terdiri dari 2 set yaitu yang diperuntukan bagi mempelai pria dan mempelai wanita. Pada pakaian adat pernikahan mempelai pria dapat ditemukan simbol matematika yakni berupa lingkaran pada bagian ikat kepala (destar/kampurui) yang mempunyai makna melambangkan kebesaran. Sedangkan pada pakaian adat pernikahan mempelai wanita juga dapat ditemukan simbol matematika berupa persegi panjang pada salah satu bagiannya, yakni pada bagian sarung yang disebut bia ogena. Tentunya, masih banyak unsur pendukung lainnya dalam pakaian adat pernikahan Buton yang dapat dikaitkan dengan matematika. Berdasarkan uraian di atas, maka peneliti tertarik untuk mengangkat judul "Eksplorasi Etnomatematika Makna Simbol Pakaian Pernikahan Adat Buton Kajian Semiotik".

Berdasarkan latar belakang di atas maka fokus masalah dalam penelitian ini yaitu apa konsep matematika pada pakaian adat pernikahan Buton dan bagaimana makna simbolik pada pakaian adat pernikahan Buton kajian semiotik?. Adapun tujuan dari penelitian ini adalah untuk mengetahui konsep matematika pada pakaian adat pernikahan Buton serta untuk mengetahui makna simbolik pada pakaian adat pernikahan Buton kajian semiotik. Selain itu manfaat yang diharapkan dari penelitian ini sebagai informasi terutama bagi pendidik agar menjadikan etnomatematika sebagai inovasi pengembangan pembelajaran matematika, sebagai sumber informasi bahwa ternyata ada konsep matematika pada pakaian adat pernikahan Buton serta sebagai sumber informasi terutama pada siswa dan masyarakat bahwa terdapat makna simbol pada pakaian adat pernikahan Buton. Adapun potensi yang didapatkan dalam penelitian ini dapat ditemukan konsep himpunan dan geometri, dan dapat dibuatkan artikel ilmiah yang nantinya akan diseminarkan. Artikel ilmiah 
ini berupa narrative review yang akan dipublikasikan dalam media cetak. Dalam bidang pendidikan, penelitian ini dapat menambah wawasan mengenai adanya keterkaitan antara kebudayaan dan matematika, sehingga dapat membantu siswa dalam memahami matematika yang sifatnya abstrak, diterbitkannya dalam jurnal nasional yang ber-ISSN serta mendapatkan HKI (Hak Kekayaan Intelektual).

Pandangan dari peneliti yang pernah melakukan pembahasan terkait penelitian ini diantaranya penelitian yang dilakukan oleh Asis \& Herianah (2020), tentang Makna Simbol Pakaian Adat Pernikahan Buton pada Golongan Каоти dan Golongan Walaka dikota Baubau: Kajian Semiotik. Hasil penelitian menunjukan bahwa terdapat makna symbol kajian semiotik pakaian adat pengantin laki-laki (Balahadada) dan pakaian adat pengantin mempelai wanita (Kombo). Senada dengan penelitian diatas Nurlaelah, program studi sejarah dan kebudayaan Islam pada tahun 2014, melalui penelitian yang berjudul Makna Simbolik Pakaian Adat Pengantin Bugis Sinjai, Sulawesi Selatan (Tinjauan Budaya) juga mengungkapkan bahwa terdapat makna simbolik pakaian Adat pengantin Bugis Sinjai yang dapat dikaitkan dengan konsep matematika. Konsep tersebut adalah konsep Geometri (Sarung yang di kingking) sarung kain yang terbuat dari kain antallasa yang kaya sarat dengan benang emas sehingga nampak mengkilat dengan motiv bunga atau daun-daunan yang melambangkan kehidupan atau hidup, mengandung makna sebagai harga diri dan moral.

\section{Metode}

Penelitian ini merupakan jenis penelitian eksploratif, penelitian eksplorasi dimaksudkan untuk menjajaki suatu fenomena baru yang mungkin belum ada pada penelitian yang dilakukan sebelumnya Mudjiyanto (2018). Penelitian ini akan dilaksanakan pada bulan Juni-Agustus tahun 2021 dan bertempat di kota Baubau Sulawesi Tenggara. Subjek dari penelitian ini adalah beberapa budayawan, sejarahwan, dan tokoh masyarakat di Baubau, Sulawesi Tenggara. Untuk mengumpulkan data yang kompleks jelas dan spesifik, peneliti menggunakan beberapa cara yakni; 1) Studi kepustakaan yaitu menghimpun informasi yang relevan dengan masalah yang menjadi topik penelitian, 2) Observasi, peneliti dapat menggunakan catatan lapangan dengan pengamatan alamiah 3) Wawancara, yakni peneliti memberikan kesempatan seluas-luasnya kepada informan dalam menjawab pertanyaan-pertanyaan yang diajukan, 4) Dokumentasi, yakni pengumpulan data yang diperoleh dari hasil meriset dokumen yang ada ditempat penelitian di daerah Buton, baik berupa foto, hasil rekaman suara, video, dokumen dan hal lain yang menunjang penelitian. Teknik analisis data yang digunakan dalam penelitian ini adalah dengan cara melakukan evaluasi terhadap pengambilan data. Evaluasi pengambilan data ini dilakukan dengan cara membuat rekaman wawancara dan mencari jurnal. Rekaman wawancara dan pencarian jurnal yang diperoleh saat pengambilan data diputar kembali, didengarkan dengan cermat dan kemudian dideskripsikan. Penentuan keabsahan data dalam penelitian ini adalah dengan menggunakan triangulasi sumber dan triangulasi antar peneliti. Triangulasi sumber dalam penelitian ini adalah dengan cara (cross-check).

\section{Hasil}

Pada pakaian adat pernikahan Buton, terdapat perbedaan dalam penggunaan aksesoris melalui kajian semiotik. Menurut Asis \& Herianah (2020) pakaian adat Buton memiliki ciri khas tersendiri, baik bagi masyarakat yang mempunyai stratifikasi sosial yang tinggi maupun orang biasa. Dalam pakaian adat tersebut, memiliki fungsi dan makna simbol tersendiri dalam penggunaannya. Pada umumnya, pakaian adat lebih cenderung dipakai oleh kaum bangsawan 
seperti sultan dan lain-lain. Pakaian pernikahan adat Buton terdiri dari 2 set yaitu yang diperuntukan bagi mempelai pria dan mempelai wanita. Pada pakaian adat pernikahan mempelai pria terdapat unsur-unsur yakni lepi-lepi (mahkota), kampurui (ikat kepala), baju balahadada, sulepe, selendang, bia samasili (sarung), sala arabu (celana arab), tobo/keris, dan kamba (rangkaian bunga). Selain itu pada pakaian adat mempelai wanita terdapat unsur-unsur yakni tipolo (penutup kepala), kambarambei (kupu-kupu), kombo, kambero (kipas), simbi (gelang), korokoronjo (cincin), punto, lonjo/bia ogena, kalegowa (saputangan), kabokena lima (pengikat tangan), sampelaka (benda) jaojaonga (kalung) berupa; 1)kambera 2)naga, dan 3)lawulu. Beberapa unsur pakaian adat pernikahan tersebut dapat ditemukan makna simbol kajian semiotik yang dapat dikaitkan dengan matematika. Berikut penjelasannya:

\section{Pembahasan}

1. Makna Simbol Pakaian Adat Pengantin Laki-Laki (Balahadada)

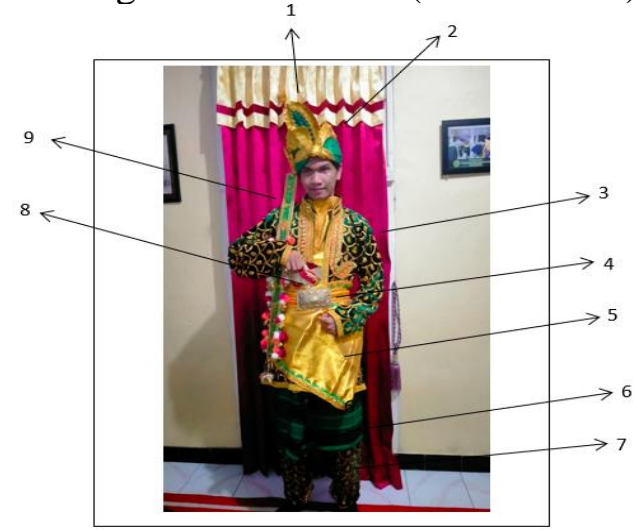

\section{Gambar 1. Pakaian adat pengantin laki-laki}

Penjelasan makna simbol pada pakaian adat pengantin laki-laki (Balahanda) dapat dilihat pada Tabel 1 berikut:

Tabel 1. Makna simbol pakaian adat pengantin laki-laki (balahadada)

\begin{tabular}{|c|c|c|c|}
\hline No. & Unsur & Makna Simbol Kajian Semiotik & Etnomatematika \\
\hline 1 & & $\begin{array}{l}\text { Mahkota atau lepi-lepi yang dipasang pada } \\
\text { bagian atas kampurui yang berlogo buah } \\
\text { nenas memiliki simbol wilayah Buton. } \\
\text { Nenas memiliki makna Ketuhanan yang } \\
\text { Maha Esa. Dalam hal ini mengandung } \\
\text { makna diluar kelihatannya kasar dan keras } \\
\text { namun pada bagian dalamnya mengandung } \\
\text { kelembutan (Wawancara MH, Juni: 2021) }\end{array}$ & $\begin{array}{l}\text { Pada Lepi-Lepi terlihat bahwa } \\
\text { ada lingkaran kecil bergaris } \\
\text { warna merah dan lingkaran } \\
\text { besar bergaris warna biru. Hal } \\
\text { ini dapat dibuat menjadi } \\
\text { gabungan dari dua himpunan } \\
\text { dimana himpunan A memuat } \\
\text { himpunan B. }\end{array}$ \\
\hline
\end{tabular}


2

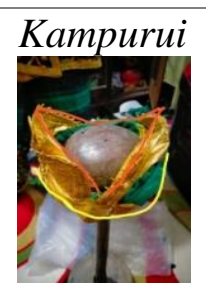

Kampurui disimbolkan sebagai makna tanda kebesaran. Simbol tersebut melambangkan sifat seseorang yang jujur, hatinya lemah lembut dan bijak (Wawancara MH, Juni: 2021). Kampurui berbentuk segitiga sama kaki. Makna simbol kampurui ini adalah melambangkan kebesaran (Wawancara BR, Juni: 2021)

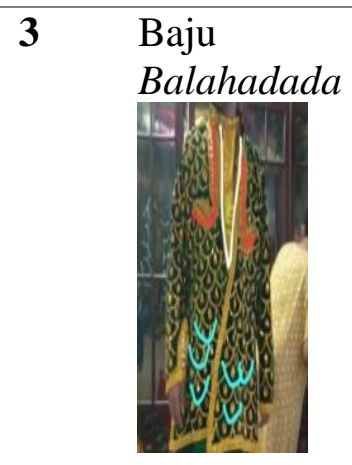

Baju Balahadada terbuat dari kain beludru dan terdapat manik-manik atau hiasan yang disebut boka-boka \& hiasan berbentuk sisik (wona). Pada bagian pertengahan dada biasanya ditempelkan belahan dada bernama Randa dan kancing baju bernama khuji (Wawancara IK, Juni: 2021). Pada leher baju hiasan Pasamani lebih besar dan mencolok dan ditempelkan Ake yang terbuat dari emas atau perak. Pada masingmasing baju, dilekatkan sebuah Ake besar yang berpangkal dari bawah leher baju langsung turun sampai perut baju.
Pada kampurui terlihat bahwa ada garis berwarna kuning jika dilihat pada dua arah terbentuk sebuah lingkaran yang mempunyai diameter. Adapun garis berwarna merah merupakan gabungan dua segitiga mebentuk segitiga sama kaki jika disatukan

Pada baju Balahadada terlihat ada garis berwarna biru berbentuk setengah lingkaran yang terbuat dari kain beludru kemudian pada belahan dada, garis merah membentuk dua sudut siku-siku. Pada pertengahan dada garis putih menunjukan segitiga sama kaki. Selain itu, kancing berbentuk kerucut segi lima.

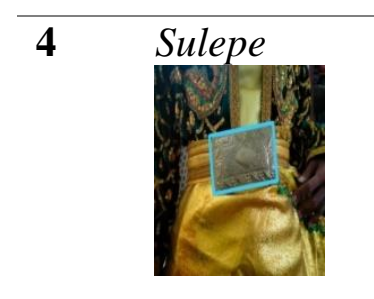

Sulepe atau ikat pinggang bermakna sebagai sebuah kekuatan atau pengukuh dalam agama dan ikatan adat (Wawancara MH, Juni: 2021). Sulepe berfungsi sebagai pengikat dan untuk menahan bia ogena agar tidak jatuh. Kepala sulepe terbuat dari logam dan talinya terbuat dari kain. Sulepe untuk orang menikah berbentuk segi empat. Kepala sulepe harus menghadap ke depan bagi laki-laki (Wawancara BR, Juni: 2021)

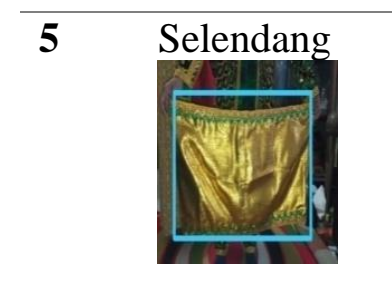

$6 \quad$ Bia Samasili

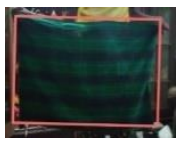

Selendang dipakai hanya untuk seorang bangsawan. Bangsawan dalam hal ini berarti Golongan kaomu dan papara. Makna dari selendang ini adalah yang berkuasa dan berpengaruh (Wawancara BR, Juni: 2021)

Bia Samasili sebagai pelapis dari baju Balahadada dan Sala arabu. Sarung ini sebagai tanda bahwa yang menggunakannya tampak lebih sopan dan berwibawa (Wawancara MH, Juni: 2021)
Kepala ikat pinggang berbentuk empat persegi panjang dengan ukiran kalimat Tauhid dan motif bunga-bunga (rongo) di sekeliling pinggirnya. Tulisan kalimat Tauhid sebagai perlambangan dan pengukuhan atau pengikat hukum agama dan adat yang harus ditaati.

Membentuk sebuah persegi panjang yang mempunyai panjang dan lebar

Membentuk persegi panjang yang mempunyai simetri putar yaitu apabila digunakan akan melakukan sebesar $180^{\circ}$ 


Sala arabu (celana arab) adalah celana Pada celana arab ini
yang memiliki kaki yang kecil, paha dan membentuk seperti tabung
pinggang yang besar (Wawancara IK, Juni: tanpa tutup karena memiliki
2021). Biasanya motif dari celana Arab ini kaki yang kecil, paha dan
disamakan dengan baju Balahadada pinggang yang besar.
(Wawancara MH, Juni: 2021)

2. Makna Simbol Kajian Semiotik Pakaian Adat Pengantin Perempuan (Kombo)

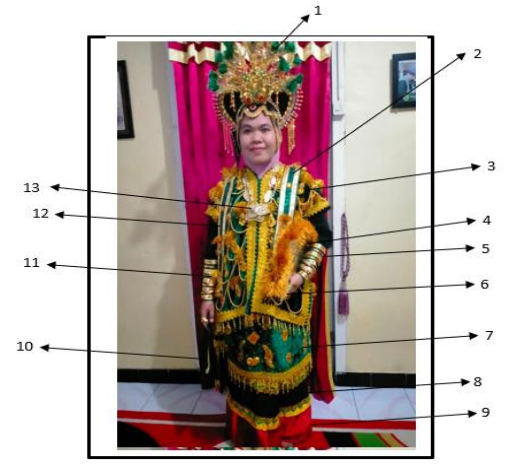

\section{Gambar 1. Pakaian adat pengantin perempuan}

Penjelasan makna simbol pada pakaian adat pengantin perempuan (Kombo) dapat dilihat pada Tabel 2 berikut:

Tabel 2 Makna simbol pakaian adat pengantin perempuan (kombo)

No. Unsur Makna Simbol Kajian Semiotik $\quad$ Etnomatematika




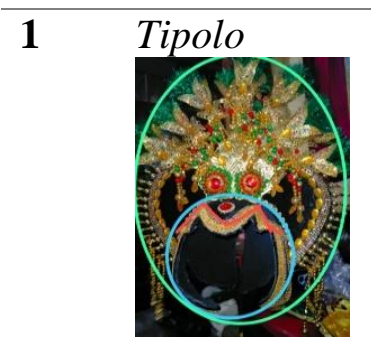

Tipolo atau penutup kepala wanita, terbuat dari kain beludru. Mempunyai hiasan berupa bigi/penyanggah bunga ija, gulu-gulu, patiga, bunga ija, dan popungu. Bigi ini berfungsi sebagai penyanggah hiasan bunga ija (Wawancara, Joni: Juni 2021).
Terlihat bahwa ada lingkaran kecil bergaris warna merah dan lingkaran besar bergaris warna biru. Hal ini dapat dibuat menjadi gabungan dari dua himpunan dimana himpunan $\mathrm{A}$ memuat himpunan $\mathrm{B}$.

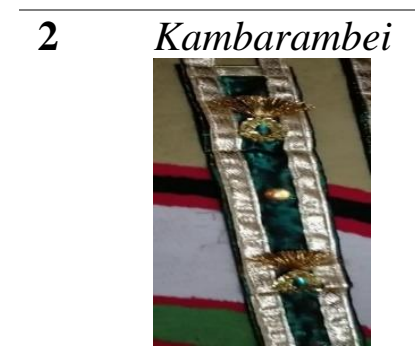
3

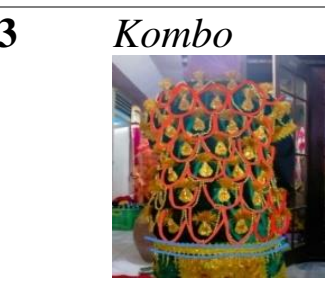

\section{Kambarambei artinya kupu-kupu,} berupa aksesoris yang bersifat tambahan pada pengantin wanita. Terbuat dari kain yang berhiaskan benang emas atau perak, biasanya dikaitkan pada bahu kiri yang bererbentuk memanjang disertai jahitan bunga. (Wawancara Joni, Juni : 2021)
Kombo adalah pakaian pengantin untuk wanita yang terbuat dari kain satin, biasanya bewarna dasar putih dihiasi dengan hiasan manik-manik, jahitan benang emas dan perak. Baju Kombo ini merupakan baju kebesaran bagi kaum wanita. (Wawancara, Joni: Juni 2021).

\begin{tabular}{|c|c|c|}
\hline 4 & Kambero & $\begin{array}{l}\text { Kambero artinya kipas, digunakan } \\
\text { sebagai pengipas agar tidak gerah } \\
\text { (Wawancara, Joni: Juni 2021). }\end{array}$ \\
\hline 5 & Simbi & $\begin{array}{l}\text { Simbi artinya gelang yang digunakan } \\
\text { pada tangan kiri dan tangan kanan } \\
\text { masing-masing } 4 \text { buah terbuat dari } \\
\text { kuningan atau emas (Wawancara, } \\
\text { Joni: Juni 2021). }\end{array}$ \\
\hline
\end{tabular}

Cincin atau korokoronjo (cincin yang bentuknya memanjang) dan dipasangkan pada ibu jari. Dipakai oleh wanita yang posuo atau pingitan dan perkawinan (Wawancara, Joni: Juni 2021).
Membentuk sebuah persegi yang mempunyai sisi yang sama, dan terdapat setengah lingkaran

Berbentuk juring lingkaran yang terdapat sudut pusat dan jari-jari

Berbentuk sebuah lingkaran
Berbentuk sebuah lingkaran, adapun yang memanjang membentuk sebuah segi lima tidak beraturan 


\begin{tabular}{|c|c|c|c|}
\hline 7 & Punto & $\begin{array}{l}\text { Punto adalah kain yang berwarna } \\
\text { hitam yang digunakan dalam pakaian } \\
\text { adat Buton. Berfungsi sebagai } \\
\text { pelindung bila ada rembesan darah } \\
\text { ketika wanita haid. (Wawancara, } \\
\text { Joni: Juni 2021). }\end{array}$ & $\begin{array}{l}\text { Membentuk gabungan- } \\
\text { gabungan bangun datar persegi } \\
\text { panjang dan persegi }\end{array}$ \\
\hline 8 & & $\begin{array}{l}\text { Bio Kobiwi adalah kain yang menyatu } \\
\text { dengan lonjo (sarung). Bio Kobiwi } \\
\text { direkatkan pada pinggiran sarung } \\
\text { lonjo memiliki arti karakter manusia } \\
\text { yang suka berbicara (Wawancara BR, } \\
\text { Juni: 2021) }\end{array}$ & Berbentuk persegi panjang \\
\hline 9 & $\begin{array}{l}\text { Lonjo/Bia } \\
\text { Ogena }\end{array}$ & $\begin{array}{l}\text { Sarung Lonjo atau disebut juga Bia } \\
\text { Ogena adalah sarung yang terdiri dari } \\
\text { gabungan beberapa macam warna } \\
\text { polos seperti merah, hitam, hijau, } \\
\text { kuning, biru dan putih dan dijahit } \\
\text { secara bertingkat-tingkat. Pakaian ini } \\
\text { adalah pasangan dari baju kombo. }\end{array}$ & $\begin{array}{l}\text { Jahitan Lonjo ini dijahit secara } \\
\text { bertingkat-tingkat seperti } \\
\text { piramida atau seperti limas }\end{array}$ \\
\hline 10 & & 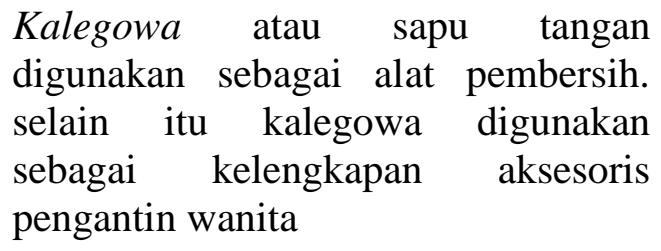 & $\begin{array}{l}\text { Membentuk sebuah segitiga } \\
\text { sama sisi }\end{array}$ \\
\hline 11 & & $\begin{array}{l}\text { Kabokena Lima atau pengikat tangan } \\
\text { dikenakan berpasangan dengan } \\
\text { gelang atau simbi. Berfungsi sebagai } \\
\text { pengikat atau penahan gelang. } \\
\text { Memiliki makna mempererat tali } \\
\text { silaturrahmi antara satu dengan } \\
\text { lainnya (Wawancara, Joni: Juni 2021) }\end{array}$ & $\begin{array}{l}\text { Kabokena Lima berbentuk } \\
\text { lingkaran }\end{array}$ \\
\hline 12 & & $\begin{array}{l}\text { Sampelaka berasal dari kata sampela } \\
\text { yang berarti benda. Sampelaka } \\
\text { hampir sama dengan kambarambei } \\
\text { hanya saja sampelaka ini dipakai di } \\
\text { bagian bahu sebelah kanan, berfungsi } \\
\text { sebagai hiasan dan kebesaran bagi } \\
\text { mempelai wanita. (Wawancara, Joni: } \\
\text { Juni 2021) }\end{array}$ & $\begin{array}{l}\text { Membentuk sebuah persegi } \\
\text { panjang }\end{array}$ \\
\hline 13 & $\begin{array}{l}\text { Jao-Jaonga } \\
\text { Kambera }\end{array}$ & $\begin{array}{l}\text { Jao-jaonga dalam bahasa Indonesia } \\
\text { berarti kalung. Jao-jaonga terbuat } \\
\text { dari kuningan. Kalung yang } \\
\text { dikenakan pada pernikahan adat } \\
\text { Buton terdiri } 3 \text { macam yaitu Naga, } \\
\text { Kambera dan yang berbentuk }\end{array}$ & $\begin{array}{l}\text { Pada bagian tengah Kambera } \\
\text { dan Lawulu berbentuk segi } \\
\text { empat tidak beraturan. Bagian } \\
\text { sisi kiri kanan kambera } \\
\text { berbentuk belah ketupat. Naga } \\
\text { berbentuk segi lima tidak }\end{array}$ \\
\hline
\end{tabular}




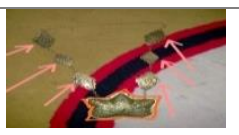

Lawulu

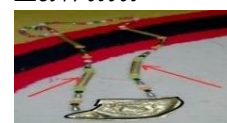

permata yaitu Lawulu. Pemakaiannya pada wanita.

Bentuknya memanjang dan terdapat jahitan bunga di pinggirnya (Wawancara, Joni: Juni 2021) beraturan dan bagian sisi kiri kanan naga berbentuk belah ketupat. Bagian sisi kiri kanan lawulu berbentuk seperti titik dan garis

\section{Kesimpulan}

Berdasarkan hasil penelitian, maka dapat diambil kesimpulan bahwa terdapat makna simbol kajian semiotik pada pakaian adat pernikahan Buton mempelai pria dan wanita yang unsurunsurnya dapat dikaitkan dalam matematika diantaranya adalah himpunan dan geometri. Himpunan yang dimaksud meliputi gabungan dari dua himpunan yaitu pada lepi-lepi/mahkota yang memiliki makna simbol wilayah Buton yaitu nenas yang memiliki makna Ketuhanan yang Maha Esa. Dalam hal ini mengandung makna diluar kelihatannya kasar dan keras namun pada bagian dalamnya mengandung kelembutan. Sedangkan konsep geometri pada pakaian adat pernikahan Buton diantaranya, persegi yaitu pada, persegi panjang, limas, kerucut, setengah lingkaran, lingkaran, belah ketupat, segitiga sama kaki, segitiga sama sisi, segi empat tidak beraturan, segi lima tidak beraturan, juring lingkaran yang terdapat sudut pusat dan jari-jari, sudut siku-siku, sudut yang lancip dan mempunyai derajat kemiringan, kerucut segi lima, dan tabung tanpa tutup.

\section{Ucapan Terima Kasih}

Dengan ini kami tim Mahasiswa Program Kreatifitas Mahasiswa Skema Riset Sosial Humaniora (PKM-RSH) dari Pendidikan Matematika Fakultas Keguruan dan Ilmu Pendidikan Universitas Dayanu Ikhsanuddin. Kami mengucapkan terima kasih kepada para pihak yang telah memberikan kontribusi pada kegiatan penelitian "Eksplorasi Etnomatematika Makna Simbol Pakaian Adat Pernikahan Buton Kajian Semiotik" :

\section{Referensi}

Asis, A., \& Herianah. (2020). MAKNA SIMBOL PAKAIAN ADAT PERKAWINAN BUTON PADA GOLONGAN KAOMU DAN GOLONGAN WALAKA DI KOTA BAUBAU: KAJIAN SEMIOTIK. Pangadereng: jurnal hasil penelitian ilmu sosial dan humaniora, Vol. 6 No. 2, 254 - 266.

Bishop, C. M. (1994). Mixture density networks. Technical Report.

Mudjiyanto, B. (2018). Tipe Penelitian Eksploratif Komunikasi. Jurnal Studi Komunikasi dan Media, 65-74.

Mulyono, A. (2003). Pendidikan bagi anak berkesulitan belajar. Jakarta : Rineka Cipta, 1999.

Risdiyanti, I., \& Prahman, R. (2017). Ethnomathematics: Exploration in Javanese culture. Journal of Physics: Conference Series, 1-6. 